\title{
¿Weather Risk Management in Marine Survey Campaigns for the Offshore Investment Projects in the Polish Exclusive Economic Zone
}

\author{
Maria Kubacka, ${ }^{a}$ Maciej Matczak, ${ }^{a}$ Maciej Katas, ${ }^{a}$ Lucjan Gajewski, ${ }^{b}$ And Marcin Burchacz ${ }^{a}$ \\ ${ }^{a}$ Maritime Institute of the Gdynia Maritime University, Gdynia, Poland \\ ${ }^{\mathrm{b}}$ MEWO S.A., Straszyn, Poland
}

(Manuscript received 17 December 2020, in final form 19 July 2021)

\begin{abstract}
Weather is a crucial factor (and the most unpredictable of all factors) determining the success or failure of any offshore activity, such as investments in seafloor grid connectors (gas, energy, or communication), development of oil and gas drilling facilities, and erection of offshore wind farms. Weather conditions cannot be foreseen accurately over a time horizon longer than a few days, and so arranging a realistic work schedule for such an enterprise poses a great challenge. This paper identifies and analyzes the greatest risks associated with weather conditions at sea. The importance and impact of weather on the project implementation are assessed and mitigating measures are proposed. As part of the work, a review of scientific literature was conducted, and the core conclusions were reached using information-gathering techniques and a documentation review of the offshore projects implemented in cooperation with the Maritime Institute. The authors based their analysis on experience from survey campaigns conducted in the Baltic Sea in the areas of the investments planned for implementation. The analysis of risks associated with weather conditions is based on the statistical weather data obtained using the Wave Ocean Model cycle 4 (WAM4). The research reveals that it is impossible to create an accurate survey schedule for long-term offshore projects; however, using statistics for each individual hydrodynamic parameter can, to some extent, facilitate the creation of survey schedules for maritime projects.
\end{abstract}

SIGNIFICANCE STATEMENT: Offshore wind energy is one of the fastest-growing industries in the world energy sector, yet there is no wind farm in the Polish Exclusive Economic Zone on the Baltic Sea. To date, however, many preinvestment studies and survey campaigns have been carried out for several such investments. Some of them were conducted by the team of the Maritime Institute of Poland. The biggest challenge for us was to plan the survey campaigns because of the weather conditions that cannot be foreseen accurately over a time horizon longer than a few days. The experience gained in the process was an inspiration to write this article in which we identify and analyze the weatherrelated risks. The obtained results, although representative for the Baltic Sea region area, are also of a more universal character and can be used by offshore managers all over the world.

KEYWORDS: Hydrometeorology; Europe; Numerical weather prediction/forecasting; Seasonal forecasting; Risk assessment

\section{Introduction}

\section{a. Marine surveys and investigations in offshore projects}

Improvement of environmental performance in the energy sector is a commonly implemented strategy, both on global and European scales. Renewable energy investments are, therefore, an important step toward the reduction of carbon emissions ("20-20-20 target") and keeping the global warming temperature below $2^{\circ} \mathrm{C}$ [target from the 21st session of the Conference of Parties in Paris (COP 21)] (Mytilinou and Kolios 2019). Also, it serves the implementation of the European Commission climate

¿ Denotes content that is immediately available upon publication as open access.

Kubacka's ORCID: 0000-0002-5146-7722.

Matczak's ORCID: 0000-0002-2985-9914.

Kałas's ORCID: 0000-0001-9341-2829.

Burchacz's ORCID: 0000-0002-8522-4470.

Corresponding author: Maria Kubacka, mkubacka@im.umg. edu.pl and energy policy framework where renewable energy should contribute to the final energy consumption from $30 \%$ to $51 \%$ in 2050 (Chaouachi et al. 2017). Thus, onshore and offshore wind energy have become an interesting option for decision-makers. Offshore wind farms (OWF) are an example among other offshore investments such as grid connectors in seafloor (gas, energy, or communication) and development of oil and gas drilling facilities. Analyzing an OWF life cycle can generally be split into four (Poulsen and Lema 2017) or five (Dedecca et al. 2016; Myhr et al. 2014) key phases with an initial predevelopment and consent (P\&C) stage. The key elements of this phase are project management, legal authorization, engineering, and contingencies as well as comprehensive seafloor surveys (Shafiee et al. 2015).

The P\&C of an OWF normally takes from 1 to 5 (Tseng et al. 2017) years (total life span of an OWF is estimated at approximately 25 years) and consumes around $14.0 \%$ of capital expenditures (CAPEX) (Shafiee et al. 2015). The survey part consisting of environmental and meteorological investigations creates $\sim 16 \%$ of the costs of the P\&C phase (Myhr et al. 2014) or $1.3 \%$ of CAPEX (Shafiee et al. 2015) of the entire investment. Since the complex and lengthy approval procedures (e.g., mandatory environmental impact assessment; Tseng et al. 2017) are 
especially relevant for offshore wind parks (Williams et al. 2017), a comprehensive scope of marine surveys is required (Gatzert and Kosub 2016). These are conducted to ensure that the offshore wind farms can be built in the right locations with the least impact on animal life or nature in general and are based on the correct seabed conditions (Poulsen and Lema 2017). Marine surveys are also necessary in the next phases of the OWF development, especially in relation to the environmental impact assessment (the before-after-control-impact framework) (Lapeña et al. 2010; OSPAR Commission 2008).

Along with the complexity of research, the limited accessibility of the survey area is also a challenge. It is estimated that the average accessibility of the offshore wind farms ranges from $60 \%$ to $70 \%$ (95\%-99\% in the case of onshore projects) (Shafiee 2015). Limited accessibility is due to ever-changing sea conditions, high weather sensitivity of the equipment and vessels (Gintautas et al. 2016), and location at a distance from the coast (Leimeister and Kolios 2018) as well as great project complexity (Douard et al. 2012). Effective weather risk management plan, where procedures used to manage weather-related risks during project implementation is well developed in the $\mathrm{P} \& \mathrm{C}$ phase, and the projects' whole life cycle is fundamental. Weather risk management plan includes weather-related risks identification and measurement, planning weather-related risk response methods, and implementation of reserve plans as well as allocation of reserves.

\section{b. Weather risk management in the offshore surveys}

According to Campbell and Diebold (2005), weather risk "is about the unpredictable component of weather fluctuations", revealed by "weather surprises." The weather risk results from the variability of atmospheric conditions that can occur for the same place in successive periods of time. This variability is understood as the deviation of the measured weather factors from their long-term average (Czekaj 2016). However, atmospheric phenomena are difficult to predict, but it does not mean that prediction is impossible. If it were possible to accurately forecast the weather over a time horizon longer than a few days, then there would be no weather risk and therefore no problem. However, despite significant developments in synoptic meteorology, it is basically possible to make a weather forecast with a satisfactory accuracy for several days ahead, which in most cases is too short of a period to be useful for sea research activities. When managers do not address risks that have negative effects on project effectiveness, it may result in various problems such as cost overruns, schedule delays, and poor quality of study.

As estimated, one-third of businesses worldwide are directly affected by weather conditions (Al-Zarrad et al. 2017). The risk exposures become more significant in businesses located in weather-sensitive areas, like at sea, or that are strictly linked to weather conditions, such as agriculture (https://wrmsglobal.com/) or the energy sector (Cogen 2020). Obviously, the weather is not the only issue in the complex array of risks (Gatzert and Kosub 2016), however, the weather risks are identified as crucial for the offshore sector. This risk appears at all stages of any offshore activity, for example, the OWF life cycle, but its character differs in its life cycle parts. Thus, for example, the weather conditions create a constant challenge for the transport between a farm and the shore. For that reason, a majority of the weather risk surveys focus on the operation and maintenance phase (Jamshidi et al. 2019; Li et al. 2016; Dalgic et al. 2015; Nielsen and Sørensen 2011).

Considering the $\mathrm{P} \& \mathrm{C}$ stage, the activities of the research team and proper utilization of survey equipment are important activities that are influenced by weather conditions. Transport to the survey areas and work carried out there can only be performed in acceptable safe states of the sea (wave height and period), and at the right wind speeds (Leimeister and Kolios 2018). Additionally, features such as good visibility or sunset and sunrise time can limit or extend the ability to conduct research activities (Dalgic et al. 2015). Bad weather conditions could prolong the process of research implementation, extending its costs and delaying the consenting procedures. It is crucial for survey companies.

Like any other risk, weather risk must be properly managed. Risk management is a process that focuses on identifying and eliminating hazards that could affect performance of investment. This process normally includes several stages such as (Shafiee 2015): identification, assessment, evaluation, control and monitoring, and mitigation. However, a simplified method points to three stages of risk management (Williams et al. 2017):

1) identification (hazard category, principal consequences, issues related to consequences, and possible causes),

2) analysis (consequences and likelihood of a risk occurrence; allocation of the risk magnitude), and

3) mitigation (mitigation type and measures, consequences and the likelihood of a risk occurrence, and updated risk magnitude for the residual risk).

The above-presented method should be implemented for the weather risks that occur when marine surveys are conducted. The implementation of the relevant methods ( $\mathrm{Yu} 2018$; Jamshidi et al. 2019), approaches (Dalgic et al. 2015), and techniques of weather risk management (Mraoua and Bari 2007; Wieczorek-Kosmala 2020) should support the planning and execution of a survey campaign. As a result, it enables the timely conclusion of research work and optimizes its costs.

\section{c. The aim and scope of geophysical surveys conducted offshore}

Preinvestment geophysical surveys at sea aim to investigate the relief and structure of the seabed including its bathymetry, geomorphology, and surface reflection profiles as well as soil substratum and the possible locations of uncovered bedrock. They include bathymetric (depth), seismic (deep structure of the seabed), magnetometer (magnetic anomalies in the soil substratum), and sonar (seabed surface character) surveys. The measurements are conducted along parallel measurement profiles so that the entire seabed of the area analyzed is covered. The surveys also aim to determine the presence and compile an inventory of objects that may affect the integrity and safety of the investment, such as pipelines, cables, wrecks, unexploded ordnance and misfires ("UXO"), and existing and abandoned (inactive) energy and communication cables as well as fishing nets (Szefler et al. 2017; Stryjecki et al. 2019).

\section{d. Survey area}

The Baltic Sea is regarded as a prospective area for the development of offshore wind farms. So far, $2.219 \mathrm{GW}$ of wind 


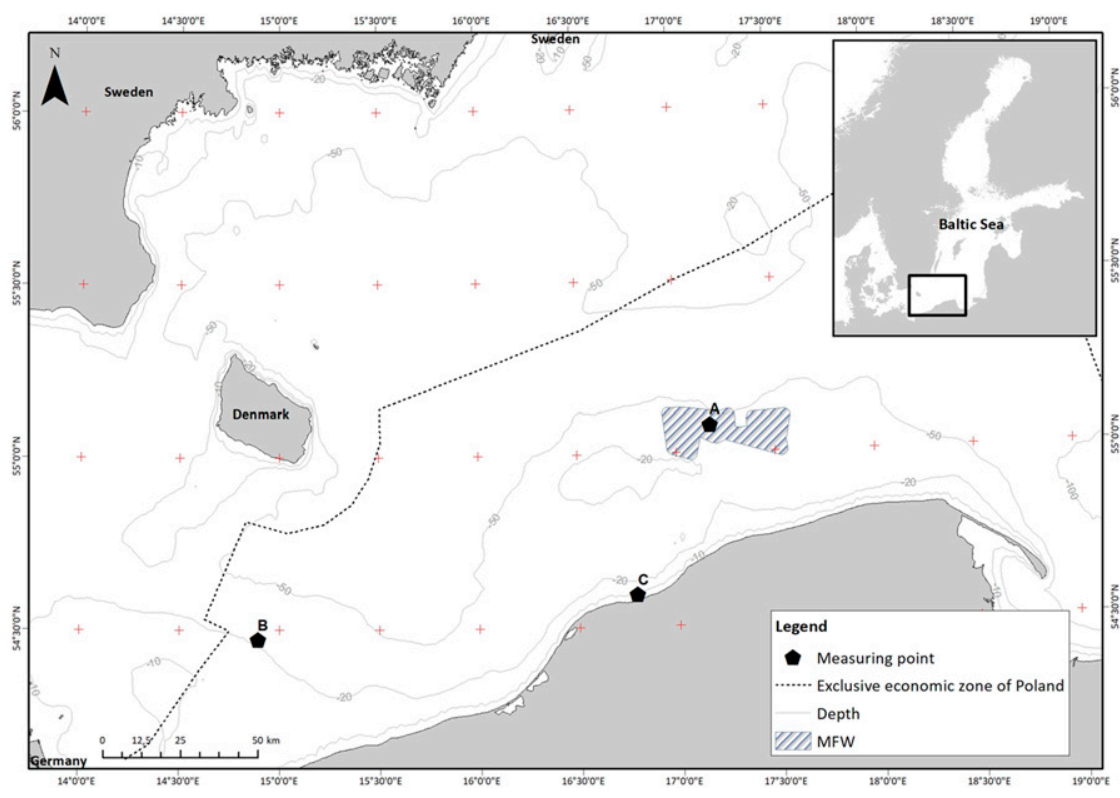

FIG. 1. Locations of the points at sea associated with the surveys performed for various hydroengineering investments.

capacity ( $10 \%$ of European capacity) has been installed in the region (WindEurope 2020). Offshore windmills are installed in Denmark, Germany, Sweden, and Finland. Poland is the last European Union country remaining at the $\mathrm{P} \& \mathrm{C}$ stage. According to the Energy Policy of Poland until 2040 (the Ministry of Climate and Environment 2020), the expected capacity of OWE should reach a level of 8-11 GW in 2040. Considering the present stage of the implementation of the OWF investments in Poland (in most cases the site selection and environmental impact assessment procedures), the first farms will begin operation around 2025. For this reason, the relevant geophysical investigations and environmental surveys are still being conducted in the Polish Exclusive Economic Zone (EEZ).

In this study, we present three research points located in the Polish EEZ of the Baltic Sea and selected for surveys and analyses. The points are placed in different geographical areas, at different distances from the coastline and are characterized by different bathymetric and geomorphological conditions. Since the selected locations can be considered representative for the Polish EEZ, the analysis of the specific meteorological and other dynamic conditions of the sea displays a full scope of works that may be implemented in the Polish marine areas in connection with offshore investments.

Two of the points are placed on the high seas, in the western (point A) and eastern (point B) parts of the Polish EEZ. Point
$\mathrm{A}$ is in the area of the planned Baltica OWF, $45 \mathrm{~km}$ from the shoreline, at a depth of $40 \mathrm{~m}$. Point B is located $35 \mathrm{~km}$ from the shore at a depth of $\sim 25 \mathrm{~m}$, on the route of the Baltic Pipe gas pipeline linking Poland and Denmark, which is currently under construction. The third point $(\mathrm{C})$ is located $1.5 \mathrm{~km}$ from the shoreline in the nearshore zone, at a depth of $12 \mathrm{~m}$. This sea area is designated for the landfall of the Baltica OWF cables. At each location preinvestment surveys were carried out: point A in 2016-17, point B from 2017 to 2019 and point C from 2016 to 2017. Detail locations and characteristics of the points are presented in Fig. 1 and Table 1.

\section{e. Problems that this paper aims to solve}

Weather conditions have significant influence on economic activities, especially in sensitive sectors such as the maritime industry. Thus, weather risk management becomes crucial for the offshore business during the whole investment process, including the preinvestment research activities.

This study aims to develop crucial elements of the weather risk management plan for offshore preinvestment geophysical surveys and for this purpose it focuses on the following research objectives: 1 ) identification of the weather-related risks in implementation of preinvestment geophysical surveys at sea, 2) assessment and quantification of identified weather-related risks and their qualification, 3 ) creating response plan for the

TABLE 1. Characteristics of the selected points at sea: coordinates $(x, y)$ in the world geodetic system (WGS) 1984, average depths $d$ in meters, distance from the shore in kilometers, and project name.

\begin{tabular}{cccccl}
\hline \hline Measuring points & $x$ & $y$ & $d$ & Distance from the shore & \multicolumn{1}{c}{ Project } \\
\hline A & 171754 & 550797 & 40 & 45 & Baltica OWF \\
B & 148944 & 544723 & 25 & 35 & Baltic-Pipe \\
C & 167917 & 545917 & 12 & 1,5 & Landfall of the Baltica OWF \\
\hline
\end{tabular}


identified weather-related risks, and 4) usage of statistical data obtain from models for identification the meteorological conditions at selected locations at sea as an example of risk response strategy. The results presented in this paper make an essential contribution to the offshore project management process. The presented findings may be used and applied by offshore managers all over the world.

The study is composed of the following parts: 1 ) We discuss offshore marine projects in the Polish EEZ, conditions suitable for conducting preinvestment research, and the importance of weather conditions in the implementation of such projects. 2) From the information-gathering techniques and the documentation review, we identified the weather-related risks that appeared in the projects. 3) All of the identified weather-related risks were analyzed (assessed, quantified, and qualified). 4) The risk-response strategy was developed by, among other methods, using data from models for the Baltic Sea. 5) The final part of the paper consists of the discussion and conclusions.

\section{Materials and methods}

\section{a. Conditions for the efficient performance of the surveys planned}

Conducting marine surveys usually requires the use of a research vessel. The type of vessel depends primarily on the survey details, that is, the distance from the place of refuge and the water depth, which is regulated by the applicable laws. Severe weather conditions may endanger the life and health of the vessel's crew, resulting in irreversible measurement errors or failures and damages to the measuring equipment. Thus, in stormy conditions, the ship does not leave the port, or if it is at the survey area, it stops operations and returns to the nearest port of refuge.

In the offshore area, the surveys are carried out aboard larger vessels, which can sail for as long as several weeks without stopovers, with the ship's working day lasting $24 \mathrm{~h}$, and the crew numbers being large enough to work in shifts. On the other hand, conducting surveys in the shallow water zone is much more difficult due to the specific bathymetric and hydrodynamic conditions (sea state) that prevail near the shore. The duration of surveys is additionally limited by the short operational time of such a vessel, which must return to a port after $12 \mathrm{~h}$.

Considering the maritime safety and work safety legislation applied and the standards specifying the acceptable weather parameters for the performance of hydrographic, geophysical, and seismoacoustic surveys, the following maximal values have been accepted for the purposes of this article: $10 \mathrm{~m} \cdot \mathrm{s}^{-1}$ for wind speed and $1.5 \mathrm{~m}$ for wave height.

\section{b. The weather-related risks identification and their qualification}

A key stage in the risk management process, that is, the risk identification, is an organized and detailed activity aimed at detecting specific types of risk occurring in a given project (Pritchard 2001). According to the Project Management Institute, the risk identification tools and techniques include documentation reviews, information-gathering techniques, checklist and assumption analyses, and diagram techniques (Project Management Institute 2000).

For the purposes of this article, the risk related to weather conditions has been identified. The necessary information was collected based on the information-gathering techniques and the documentation review of the offshore investment projects in the Polish EEZ implemented in cooperation with the Maritime Institute. Documentation included projects carried out at designated points (Fig. 1; Table 1) and additionally the environmental surveys conducted to obtain a permit for the construction of a nuclear power plant in two locations: Lubiatowo-Kopalino and Żarnowiec, Poland. These surveys covered a sea area limited by a line parallel to the shore located $8.5 \mathrm{~km}$ from the shore (Polska Grupa Energetyczna 2015). The analysis also takes into consideration the preinvestment surveys in the areas of expected construction aggregate exploitation, which are located at a distance from 2 to $8 \mathrm{~m}$ from the shoreline (Hac et al. 2011a,b), as well as the survey campaigns for the investment projects Baltica-2, Baltica-3 (Szefler et al. 2017), and Baltic Power OWFs (https://www.balticpower.pl).

A documentation review consists of careful analysis of the relevant documents, with a clear goal to identify the risks that may arise during the project implementation (Pritchard 2001). In this case, the most important documents analyzed were the daily progress reports (DPR). The DPRs filled in by the party chief and sent to the project manager every day for the ongoing control of work implementation and progress. The reports cover $24 \mathrm{~h}$ and include, among others, the current position of the vessel, short descriptions of work performed on board, observed weather conditions, conducted operational works at sea, and a summary of work planned for the following $48 \mathrm{~h}$. The information that was of particular interest included the number and duration of research vessels layovers caused by adverse weather conditions. We also looked into cases when the work was not carried out even though the weather conditions were favorable.

The information-gathering techniques allow for making unambiguous and transparent observations that describe the project risks. For the purposes of the study the Delphi technique was mostly used; therefore, questionnaires were filled out during conversations with the 18 people directly engaged in the implementation of offshore projects. The interviewees were both office workers (the project managers - 4; members of the project team-6) and people conducting work at sea (surveyors-8). The questions concerned all weather-related issues that can affect the implementation of the offshore projects. We compared the responses with the results of the documentation review and compiled a list of risks. The next step was to present all the identified risks and ask the interviewees for an assessment of the probability of listed events and their consequences. The last stage concerned questions about actions that can be taken to reduce or eliminate listed risks.

As a result of the documentation analysis and interviews, five main weather-related issues were identified. A fundamental problem that occurred to be beyond control is vessel layover or the suspension of research surveys caused mostly by natural conditions - the weather. The necessity to perform surveys in cyclical storm periods may have a considerable impact on their economics, that is, the ratio between the spell of 
TABLE 2. Compilation of risks for offshore investment projects related to the unpredictable weather conditions. Source: internal data.

\begin{tabular}{|c|c|c|c|c|c|c|}
\hline Symbol & Description & Source & Nature & May lead to & Effect & $\begin{array}{l}\text { Occurrence } \\
\text { probability }\end{array}$ \\
\hline $\mathrm{R} 1$ & $\begin{array}{l}\text { Surveys timed for } \\
\text { the storm period }\end{array}$ & Internal/external & $\begin{array}{l}\text { Organization/forces } \\
\text { of nature }\end{array}$ & $\begin{array}{l}\text { Inaccessibility of the area } \\
\text { for surveys; need to } \\
\text { repeat a part of surveys }\end{array}$ & $\begin{array}{r}\text { Time-frame } \\
\text { extension }\end{array}$ & $\begin{array}{l}\text { Highly } \\
\text { probable }\end{array}$ \\
\hline $\mathrm{R} 2$ & $\begin{array}{l}\text { Severe weather } \\
\text { conditions outside } \\
\text { the storm period }\end{array}$ & External & Forces of nature & $\begin{array}{l}\text { Inaccessibility of the area } \\
\text { for surveys; need to } \\
\text { repeat a part of surveys }\end{array}$ & $\begin{array}{r}\text { Time-frame } \\
\text { extension }\end{array}$ & Probable \\
\hline $\mathrm{R} 3$ & $\begin{array}{l}\text { Failure to start surveys } \\
\text { despite favorable } \\
\text { weather conditions }\end{array}$ & Internal & Human error & $\begin{array}{l}\text { Vessel layover despite } \\
\text { favorable weather } \\
\text { conditions }\end{array}$ & $\begin{array}{r}\text { Time-frame } \\
\text { extension }\end{array}$ & Unlikely \\
\hline $\mathrm{R} 4$ & $\begin{array}{l}\text { Measurement gear } \\
\text { breakdown }\end{array}$ & Internal/external & Organization/technical & $\begin{array}{l}\text { Need to repeat part of the } \\
\text { surveys; layover despite } \\
\text { favorable weather } \\
\text { conditions }\end{array}$ & $\begin{array}{r}\text { Time-frame } \\
\text { extension }\end{array}$ & Unlikely \\
\hline R5 & $\begin{array}{l}\text { Possible conflict with } \\
\text { other users of the } \\
\text { sea area }\end{array}$ & External & Organization & $\begin{array}{l}\text { Vessel layover despite } \\
\text { favorable weather } \\
\text { conditions/change } \\
\text { of organization }\end{array}$ & $\begin{array}{r}\text { Time-frame } \\
\text { extension }\end{array}$ & Unlikely \\
\hline
\end{tabular}

good weather and time with conditions preventing the performance of geophysical surveys. The most important issue, however, is to identify the meteorological conditions in the area where the long-term geophysical surveys are planned.

Adverse weather conditions also occur outside the cyclical storm periods; thus, introducing an element of risk into the process of survey work planning. The DPR forms also indicate that directly after the storm conditions subside, so-called swell waves may occur, which prevent further conduct of surveys despite favorable wind conditions.

Another important issue is the human factor, that is, refraining from deciding to begin the measurements at sea despite favorable weather conditions. The decision-makers on board a vessel are the captain and the party chief. The captain is responsible for the crew safety and technical condition of the water vessel at all times. Based on the weather forecast, the captain decides whether the vessel may leave the port and conduct surveys. The party chief is responsible for the implementation and quality of surveys. The party chief decides whether the prevailing weather conditions allow the performance of the measurement works and the collection of good-quality data.

Since geophysical surveys require relatively good weather conditions to be conducted properly and effectively, a conflict associated with sharing the surveyed sea area with other users is another risk. A period of poor weather also means downtime for other users of the sea area engaged, for example, in fisheries, the implementation and operation of offshore construction, or other surveys. As soon as adverse weather conditions end, the other users may start to generate the risks for the survey performance forcing the survey cancellation or its reorganization.

The last of the risks identified is a technical factor, which covers situations such as equipment failure, including vessel breakdown resulting from weather conditions. The most common causes of failures include random events, poor maintenance of equipment or its usage without following instructions, lack of personal responsibility for the technical state of equipment in the survey team, and their lack of experience in setting the weather limits for handling, and, primarily, safe loading of the measuring equipment on board.

All of the risks identified have been classified in terms of their causes, results, and occurrence probability (Table 2). With regard to their cause, the risks were categorized into two groups: the risks caused by external factors, that is, ones outside human control (such as forces of nature) and the risks caused by internal factors associated with the way the project was planned and the human factor. For each risk, its consequences for the project implementation and the occurrence probability have also been ascribed. The risks identified are indicated with symbols R1, R2, R3, R4, and R5.

\section{c. Risk assessment and quantification}

Each type of risk can be assessed in terms of its probability and severity. The measurement of risk makes it possible to determine the overall level of risk in a project as well as its value expressed in terms of cost or duration. This value often determines the level of reserves or their part (Pritchard 2001). To assess the risk associated with weather conditions, a probability and consequence class assessment matrix has been developed for the delays in completion of survey works at sea in relation to the work schedule. Probability of risk occurrence and impact on the work schedule have been determined for each type of risk. The probability of the risk occurrence was determined in percentage. Very unlikely events (less than $1 \%$ chance) are not expected to occur but cannot be excluded. Unlikely events ( $1 \%-10 \%$ chance) mean such an event occurred in the past and cannot be completely ignored. Probable events (10\%-35\% chance) occurred in the past (but are not common) and even though the conditions for the implementation of the present project are different, they are quite a real possibility. Very probable events $(35 \%-60 \%$ chance) occurred several times in the last few years, whereas almost certain events (more than $60 \%$ chance) occurred frequently in previous projects. 


\begin{tabular}{|l|c|c|c|c|c|}
\hline \multirow{2}{*}{ time } & very low & low & moderate & high & very high \\
\cline { 2 - 6 } & $\begin{array}{c}<2 \\
\text { weeks }\end{array}$ & $\begin{array}{c}2-4 \\
\text { weeks }\end{array}$ & $\begin{array}{c}1-2 \\
\text { months }\end{array}$ & $\begin{array}{c}2-4 \\
\text { months }\end{array}$ & $\begin{array}{c}>4 \\
\text { months }\end{array}$ \\
\hline almost certain (>60\%) & & & & & \\
\hline very probable (35-60\%) & & & & & R1 \\
\hline probable (10-35\%) & & & R2 & & \\
\hline unlikely (1-10\%) & & R3, R5 & R4 & & \\
\hline very unlikely (<1\%) & & & & & \\
\hline
\end{tabular}

\begin{tabular}{|l|l|l|}
\hline low & moderate & high \\
\hline
\end{tabular}

FIG. 2. Risk classification matrix, as developed from research data by the Maritime Institute of the Gdynia Maritime University.

The source data for the process of creating systems of assessment are the assessments of the probabilities and severities of individual types of risk by people involved in the implementation of offshore projects. The impact scale of each risk was determined in terms of its consequences on the project schedule and time delays. Consequences of very low impact were defined as delays of less than 2 weeks. Low impact was determined as 2-4-week delays, moderate impact as 1-2-month delays, high impact as 2-4-month delays, and very high impact as more than 4 months. In Fig. 2 the red cells indicate that the risk is unacceptable, and the yellow cells present a risk that can hardly be accepted. Such a risk calls for counteractive measures. A risk classified in the highest group (red cells) is of top priority, and the information on it must be passed to the upper-level management officers, for example, the project council, the contract manager on the ordering party's side, or even the investor. If the risk is marked as a green cell, it means it is acceptable.

\section{d. Risk response planning}

The development of risk response methods is a key stage in the risk management process. The process specifies the actions through which the problems with particular types of risk identified during the identification, classification and quantification processes are to be solved (Pritchard 2001) in response to the negative risks of projects, the "Project Management Body of Knowledge" describes four strategies: avoid, transfer, mitigate, and accept. According to Pritchard (2001), avoidance is modifying the project in order to eliminate a given risk or the factors that determine the risk by, for example, increasing the amount of time intended for the project implementation. Transfer strategy is transferring the adverse effects and responsibility for the consequences of risk onto an individual or an organization, for example, insurance, adequate provisions in the contract, bank guarantees, or warranty. Risk transfer does not remove it from the project but forces others to deal with it, and it should therefore be used with caution (Wyrozębski 2012). Risk mitigation is the most common of all risk response strategies. This process involves taking specific actions to reduce the probability and/or severity of a risk. The manager must develop a risk mitigation plan and then oversee the activities carried out according to that plan. Risk mitigation may involve the reduction of the probability of a risk occurring or the minimization of its severity if the risk does occur (Pritchard 2001). Acceptance means introducing no changes in the project plan in relation to a specific risk. Based on the gathered information we have compiled examples of response strategies for identified weather-related risks, which will be presented in section $3 \mathrm{c}$.

\section{e. Determination of weather conditions at sea based on data from the models}

We analyzed wind conditions and significant wave heights for the three selected points in the Polish EEZ in the southern Baltic (Table 1; Fig. 1). The analysis was based on the relevant data from a period of 7 years (March 2013-February 2020) obtained from the operational weather forecasting models for the Baltic Sea: the mesoscale model of the atmosphere unified model (UM) calculated operationally at the Interdisciplinary Centre for Mathematical and Computational Modeling, University of Warsaw (ICM UW) (Herman-Iżycki et al. 2002), and the wind-generated Wave Ocean Model (WAM) calculated at the Maritime Institute, Gdańsk (Komen et al. 1994). The analysis used model data calculated based on 4-km (wind) and $1 \mathrm{n} \mathrm{mi} \mathrm{(wave} \mathrm{motion;} 1 \mathrm{n} \mathrm{mi}=1.852 \mathrm{~km}$ ) grid cells for the points closest to the locations surveyed, with a time step of $1 \mathrm{~h}$, from the prognostic calculations. Since the weather forecast calculations are operationally conducted four times per day (every $6 \mathrm{~h}$ up to $60 \mathrm{~h}$ ahead), for our purposes, data from the six earliest hours have been taken. Such a choice of model data guarantees that it mirrors the conditions prevailing at sea as closely as possible (Kałas et al. 2002).

In the calculations conducted for determination of the time available for the conducting of works in the sea area, it was accepted that the two parameters (wind conditions and significant wave heights) are of key importance and a situation in which both of them occur at once was considered. However, other factors hampering the conduct of works, for example, meteorological (icing, restricted visibility, etc.) and hydrological (ice conditions, strong currents, etc.) conditions or day lengths were ignored as, in the climate conditions of the southern Baltic, their significance in conducting preinvestment geophysical surveys is limited.

\section{Results}

\section{a. Weather conditions at the selected points at sea}

Taking into account the above assumptions, the results of the calculations of the time (in percent of the period analyzed) available during the entire year and individual months for the performance of offshore surveys described above are presented in Table 3 and Fig. 3. 
TABLE 3. Time available (as a percentage of the entire period analyzed) for works at the selected points in the Polish EEZ in the Baltic Sea, by month (1-12). The wave data are derived from computation with WAM at the Maritime Institute. The wind data are derived from operational computations of weather forecasts from the mesoscale atmospheric UM at ICM UW.

\begin{tabular}{|c|c|c|c|c|c|c|c|c|c|c|c|c|c|}
\hline Station & 1 & 2 & 3 & 4 & 5 & 6 & 7 & 8 & 9 & 10 & 11 & 12 & Year \\
\hline A & 56.37 & 64.48 & 77.80 & 84.09 & 91.63 & 88.89 & 87.36 & 86.03 & 76.42 & 64.94 & 64.21 & 46.60 & 74.07 \\
\hline B & 50.83 & 60.08 & 71.47 & 77.10 & 85.77 & 83.95 & 81.43 & 82.07 & 72.45 & 62.33 & 59.01 & 40.76 & 68.93 \\
\hline $\mathrm{C}$ & 63.25 & 70.41 & 79.22 & 82.00 & 88.06 & 88.79 & 84.51 & 87.32 & 79.82 & 72.37 & 71.73 & 56.45 & 76.99 \\
\hline
\end{tabular}

\section{b. The wind and wave conditions in the sea areas of the southern Baltic}

The analysis of the time available for conducting work at sea in selected locations of the Polish EEZ presented in section 3a demonstrates significant variability throughout the year. The most favorable conditions for conducting surveys are in the spring and summer months (from May to August). The proportion of time available for conducting work in this period exceeds $80 \%$, reaching the maximum for the open sea area in May (86\%-92\%) and for the coastal waters in June (88\%). In the autumn, this share decreases systematically, reaching the minimum in December of $41 \%-47 \%$ for the open sea area and $56 \%$ for the coastal waters. In the following winter and spring months, a gradual increase occurs there (Table 3; Fig. 3). The greatest variability of the time available (up to $45 \%$ ), as well as the lowest values occur at a considerable distance from the seashore $(\sim 40 \mathrm{~m})$, while in its vicinity, the fluctuations between different seasons are smaller (up to $32 \%$ ).

The presented possibilities of performing work at sea during the year are closely related to the climatic conditions of the southern Baltic areas. This becomes apparent when we take into account the average monthly wind speeds over the sea areas analyzed (Table 4; Fig. 4) and the average monthly wave heights (Table 5; Fig. 5). The highest average monthly wind speeds as well as the highest average wave heights occur in December. However, in relation to the annual averages, the highest average wind speeds occur in the eastern part of the EEZ (location $\mathrm{A}-7.75 \mathrm{~m} \cdot \mathrm{s}^{-1}$ ), whereas the highest average wave heights occur in the western part (location B-1.11 m). For the sea areas located at a relatively short distance from the coast $(\sim 10 \mathrm{~m})$, these values are slightly lower $-7.01 \mathrm{~m} \cdot \mathrm{s}^{-1}$ for the wind speed and $0.99 \mathrm{~m}$ for the wave height. In the period analyzed, the highest wind speed of $27.23 \mathrm{~m} \cdot \mathrm{s}^{-1}$ was recorded on 5 December 2013 (location A), and the highest wave height of $6.92 \mathrm{~m}$ was on 6 December 2013 (location B).

\section{c. Response plan for the weather-related risk}

This section describes in detail identified weather-related risks and the proposals of response strategies (Table 6). Surveys timed for the storm period (R1) often happen as a result of the complexity of the project. Major investments, which may be planned for a period when the weather conditions at sea should, based on previous observations, be favorable for the implementation of offshore surveys, may get considerably extended in time, which means that an updated schedule will cover the stormy months. There are also projects in which surveys are scheduled for 12 months. The key condition for meeting the deadlines is the proper planning of the work schedule and making allowances for possible departures from the original action plan with enough time margin for individual tasks. As an avoidance strategy, a risk weight has been calculated for each month of vessel's operation at sea in a specific location (Table 7). The risk weight is based on statistical data from a wave motion model (section $3 b$ ). The time reserve expressed in a few work days allotted for an individual task depending on the month and the location at which the works are conducted has been proposed. Another proposed mitigation strategy for the risk is its transfer by including in the contract additional provisions to transfer the risk of schedule extension due to the weather conditions unsuitable for survey implementation to the principal.

Severe weather conditions outside the storm period (R2) (e.g., thunderstorm) may occur in any month of survey conduct, thus possibly interrupting the measurements conducted at that time and, consequently, delaying the task completion. A proposed avoidance strategy suggests allocating a time reserve for individual tasks in the schedule to prevent possible deviations from the action plan. Another suggested form of a risk response is its transfer by including in the contract additional provisions to transfer the risk of schedule extension due to the weather conditions unsuitable for survey implementation to the principal. This, however, requires that terms such as "force majeure" and "boundary weather conditions" are clarified in the contract, and that the duration of adverse weather conditions included in the base of the contract value is clearly specified.

Failure to start surveys despite favorable weather conditions (R3) may occur on board the ship when a conflict arises between the captain and the party chief whether to start the measurement works. It may also happen that both decide the

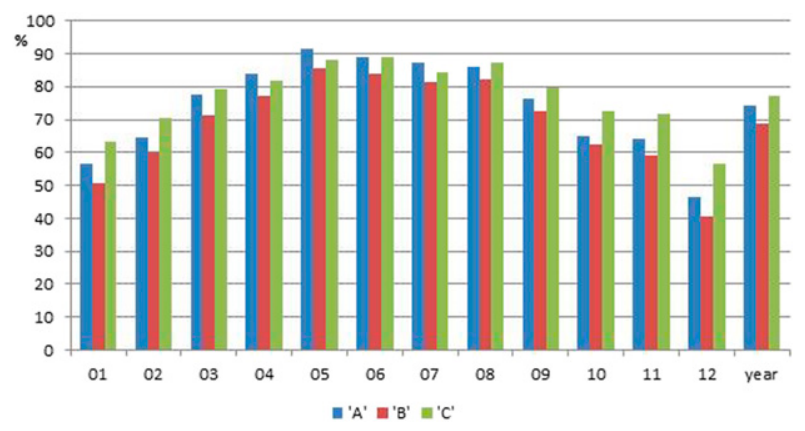

FIG. 3. The share of time available (as a percentage of the entire period analyzed) in individual months at the selected points in the Polish EEZ in the Baltic Sea. 
TABLE 4. Average wind speeds $\left(\mathrm{m} \cdot \mathrm{s}^{-1}\right)$ at the selected points in the Polish EEZ in the Baltic Sea, by month (1-12). The wind data are derived from operational computations of weather forecasts from the mesoscale atmospheric UM computed at the ICM UW.

\begin{tabular}{ccccccccccccrr}
\hline \hline Station & 1 & 2 & 3 & 4 & 5 & 6 & 7 & 8 & 9 & 10 & 11 & 12 & Year \\
\hline A & 9.62 & 8.69 & 7.54 & 6.91 & 6.08 & 6.04 & 6.45 & 6.65 & 7.64 & 8.64 & 8.66 & 10.12 & 7.75 \\
B & 9.31 & 8.39 & 7.37 & 6.85 & 6.12 & 6.1 & 6.36 & 6.54 & 7.42 & 8.13 & 8.68 & 9.48 & 7.56 \\
C & 8.59 & 7.71 & 6.73 & 6.51 & 5.68 & 5.66 & 6.17 & 5.97 & 6.83 & 7.54 & 7.62 & 9.16 & 7.01 \\
\hline
\end{tabular}

ship should not leave the port despite good weather. Decisions on suspending operations due to weather conditions should be made by the party chief and the captain after joint consultations and weather analysis (forecast and the comparison of the forecast with the current state as well as the recent forecast accuracy). A proposed strategy is mitigation of the risk. The analysis should be aimed at ensuring safe working conditions for people and acceptable conditions for data acquisition. It is proposed to consider the correlation between the available (at least two) weather forecasts, and the correlation of the forecast with the current conditions. In case of discrepancies between the forecasts, increased caution should be exercised, and when the forecasts do not envisage the current conditions, the time reserve should be additionally increased while making decisions. It is also proposed to ban the crew from disembarking the ship during its stay in a port. An introduction of such a ban is supposed to ensure a quick mobilization and readiness of the ship to begin survey activities.

Measuring equipment breakdown (R4), including ships, may be random events or consequences of improper maintenance as well as noncompliance with procedures or instructions on the use of a given device. Consequently, instead of conducting measurements in a spell of favorable weather, the ship remains in port until the necessary repairs are made. The mitigation strategy for the risk of a breakdown is proposed by regular maintenance, ongoing repairs and services of the ship, and the measuring equipment. Another example is to provide training and allow the crew to constantly develop their skills, also during their stay in port. The best practice mitigating the risk of unplanned lapses in the implementation of a project is to delegate the responsibility for individual elements of the measurement sets to individual risk owners and a daily control of their commitment to mitigating the risk impacts. Usually, this control is conducted via toolbox talks organized in daily cycles for each shift.

The last identified weather-related risk is possible conflict with other users of the sea area (R5). The proposed strategy is to avoid the conflicts within the survey area where several research vessels conduct surveys simultaneously, it is necessary to set the priority for each vessel and each activity. The captains of research vessels in advance must have knowledge about the planned presence of other vessels in the survey area.

\section{Discussion}

\section{a. Reference to the main research objectives}

The aim of the research was to develop the weather risk management plan for preinvestment geophysical surveys at sea. For this purpose, identification of the weather-related risks was made. All identified risks were assessed, quantified, and qualified, and for each risk a response plan was created.

\section{b. Summary of the main findings of the article}

Five weather-related risks were identified: surveys timed for the storm period (R1), severe weather conditions outside the storm period (R2), failure to start surveys despite favorable weather conditions (R3), breakdown of measuring gear (R4), and possible conflicts with other users of the sea area (R5). To our best knowledge, this work is the first one that undertook the identification of weather-related risks in the implementation of preinvestment surveys in offshore projects. However, weather is a source of risks in many types of other economic activities, for example, agriculture (Gobin 2017), construction (Al-Zarrad et al. 2017), tourism (Franzoni and Pelizzari 2016), transport (Meyer et al. 2012), or energy (Wieczorek-Kosmala 2020). Unfavorable weather conditions often have significant impact on demand or, in extreme cases, may prevent the normal functioning of a particular entity or group of entities in a given location. Yet the strength of the weather risk impact is not the same in every case (Mentel and Nakonieczny 2019). According to Barrieu and Scailett (2010) the impact of weather is also very predictable: the same causes will always lead to the same effects. Consequently, development risk response strategy is crucial.

Risk R1 was found to occur in projects in which the implementation time lasts several months or its original duration is extended. Risk sources have been identified as both external and internal. Internal sources were listed as inadequate planning of work schedule when the survey was arranged in a period of unfavorable weather at sea; external sources were listed when the implementation of the project was delayed due to reasons beyond peoples' control. The occurrence of such an event was determined with high probability and a very high

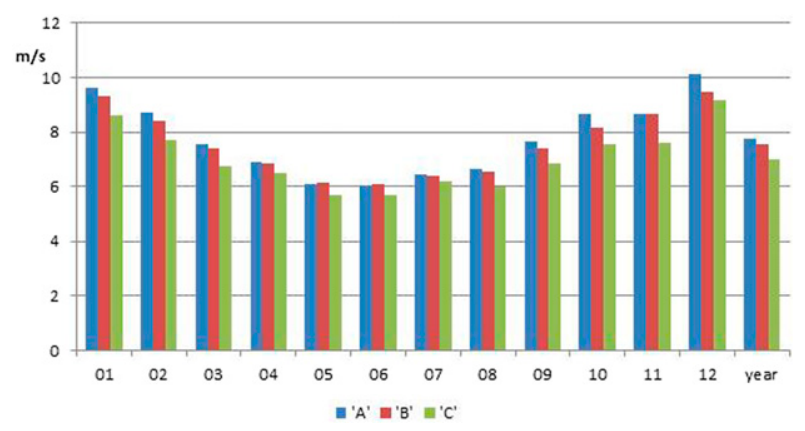

FIG. 4. Mean wind speeds $\left(\mathrm{m} \cdot \mathrm{s}^{-1}\right)$ by month at the selected points in the Polish EEZ in the Baltic Sea. 
TABLE 5. Mean wave heights (m) at the selected points in the Polish EEZ in the Baltic Sea, by month (1-12). The wave data are derived from computation with WAM at the Maritime Institute.

\begin{tabular}{|c|c|c|c|c|c|c|c|c|c|c|c|c|c|}
\hline Station & 1 & 2 & 3 & 4 & 5 & 6 & 7 & 8 & 9 & 10 & 11 & 12 & Year \\
\hline A & 0.9 & 0.76 & 0.72 & 0.69 & 0.56 & 0.57 & 0.66 & 0.53 & 0.7 & 0.79 & 0.73 & 1.02 & 0.72 \\
\hline B & 1.49 & 1.27 & 1.11 & 0.98 & 0.78 & 0.79 & 0.88 & 0.82 & 1.06 & 1.29 & 1.23 & 1.65 & 1.11 \\
\hline $\mathrm{C}$ & 1.26 & 1.09 & 1.01 & 0.91 & 0.77 & 0.72 & 0.79 & 0.75 & 0.95 & 1.12 & 1.09 & 1.34 & 0.99 \\
\hline
\end{tabular}

impact on the work schedule with consequences on the implementation time of the project that could be extended for even more than 4 months. According to Naresh et al. (2021) a 7 -day weather forecast is about $80 \%$ reliable. Shorter time scales are more so with a 5-day weather forecast about $90 \%$ correct. Forecasts longer than seven days, especially 10-day forecasts or longer tends to be only about $50 \%$ accurate. As the atmosphere is constantly changing, estimates over long periods have proved to be very difficult to model and predict. The strategy for the risk avoidance is to create a special time reserve (a risk weight) expressed in a work days, which depends on the month of the year and the location at which the works are conducted. The proposed risk weights are based on statistical data from a wave motion model. In our research, three different locations were selected to show the variation in sea conditions at the same time. According to Barrieu and Scailett (2010), weather risk has some specificities as compared with other sources of economic risk: in particular, it is a local geographical risk, which cannot be controlled. Analyzing the above, it becomes clear that addressing the R1 risk was based on a regional analysis of relevant parameters. According to Gajewski et al. (2016) and Kałas and Szefler (2016) information from several different points is enough to assess the hydrodynamic conditions for larger, adjacent areas in the Baltic Sea, thus our results should ensure representativeness for the potential survey areas, which can be located at presented measuring points (Fig. 1).

The statistics obtained from the wave motion model indicate that the weather conditions in the period from March to September are much more favorable for conducting surveys at sea than in October-February. Scheduling work for the summer period does not, however, guarantee the continuity of work. Although the average wave height at both survey points are within $1-1.3 \mathrm{~m}$ throughout the year, the maximum wave height reaches a minimum of $3 \mathrm{~m}$. Storms can occur during the whole year and the time a vessel waits in the port for favorable weather conditions can be just as long in the summer as in the winter months. Relative to the model statistics, the actual standby time due to unfavorable weather in the months selected is longer. The completed survey campaigns provided data on the weather standbys in individual months of the ships engaged in the surveys. The collection of continuous data covering several years of conducting such surveys in the Polish EEZ was, however, impossible. Since all the projects considered are commercial projects and the data collected are subject to a confidentiality clause, we cannot disclose their details. We can, nevertheless, compare the measurements made in selected months. In May, the standby caused by the unfavorable weather conditions during the geophysical surveys conducted at that time constituted $40 \%$ in 2011 , and $42 \%$ in 2020 . The statistical data from the model indicate that unfavorable weather conditions in May for all three possible locations reach at most $15 \%$. In June 2020, the weather-related standby was $33 \%$, and the statistical data indicate again about $15 \%$. In October 2016 , one of the ships stayed in port $93 \%$ of the time due to bad weather conditions, while the statistics show that it is possible to conduct surveys almost $65 \%$ of the time. In November 2017, the waiting time for acceptable weather was $58 \%$.

Weather phenomena are seasonal and change over time. An example is the occurrence of seasons. This does not mean, however, that weather phenomena are predictable within given seasons, but only that there are certain features specific to a given period. Severe weather conditions outside the storm period (R2) may occur in any month of survey conduct. Probability of such an event was determined as probable with consequences to the schedule with a delay even of up to two months. The one-time environmental impact of R2 is much smaller than that of the R1 risk, but the overall environmental impact, measured over a longer period, is noteworthy. A first proposed risk response strategy was avoidance. As we have no influence on the weather conditions, we can plan to schedule activities in such a way that we allow for additional time reserves in the event of storms or sudden weather changes.

The second proposed risk response strategy for R1 and $\mathrm{R} 2$ is transfer by including in the contract additional provisions to transfer the risk of schedule extension due to the weather conditions unsuitable for survey implementation to the principal.

Failure to start surveys despite favorable weather conditions (R3) was determined as unlikely even though such an event occurred in the past. Consequences to the schedule are determined

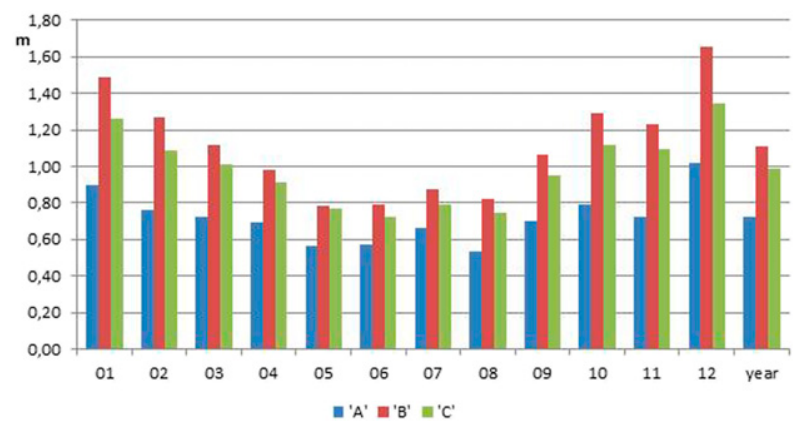

FIG. 5. Mean wave heights (m) by month at the selected points in the Polish EEZ in the Baltic Sea. 
TABLE 6. The summary of strategies for identified weather-related risks, with examples.

\begin{tabular}{|c|c|c|}
\hline Risk & Strategy & Example \\
\hline \multirow[t]{3}{*}{$\mathrm{R} 1$} & Avoidance & $\begin{array}{l}\text { Using statistical data from a wave motion model for time reserve expressed in a few workdays allotted for an } \\
\text { individual task depending on the month and the location at which the works are conducted }\end{array}$ \\
\hline & Transfer & $\begin{array}{l}\text { Including in the contract additional provisions to transfer the risk of schedule extension due to the weather } \\
\text { conditions unsuitable for survey implementation to the principal }\end{array}$ \\
\hline & & Clarifying in the contract terms such as "force majeure" and "boundary weather conditions" \\
\hline \multirow[t]{3}{*}{$\mathrm{R} 2$} & Avoidance & Considering possible deviations from the action plan and allocating a time reserve for individual tasks in the schedule \\
\hline & Transfer & $\begin{array}{l}\text { Including in the contract additional provisions to transfer the risk of schedule extension due to the weather } \\
\text { conditions unsuitable for survey implementation to the principal } 2\end{array}$ \\
\hline & & Clarifying in the contract terms such as "force majeure" and "boundary weather conditions" \\
\hline \multirow[t]{3}{*}{ R3 } & Mitigation & $\begin{array}{l}\text { Making decisions on suspending operations due to weather conditions by the party chief and the captain after joint } \\
\text { consultations }\end{array}$ \\
\hline & & Regular weather analysis (comparison of the forecast with the current state as well as the recent forecast accuracy) \\
\hline & & $\begin{array}{l}\text { Banning the crew from disembarking from the ship during its stay in a port to ensure a quick mobilization and } \\
\text { readiness of the ship to begin a survey cruise }\end{array}$ \\
\hline \multirow[t]{3}{*}{$\mathrm{R} 4$} & Mitigation & Regular maintenance, ongoing repairs, and services of the ship and the measuring equipment \\
\hline & & Providing training and allowing the crew to constantly develop their skills, also during their stay in port \\
\hline & & $\begin{array}{l}\text { Delegating the responsibility for individual elements of the measurement sets to individual risk owners and a daily } \\
\text { control of their commitment }\end{array}$ \\
\hline \multirow[t]{2}{*}{ R5 } & Avoidance & Setting the priority for each vessel and each activity \\
\hline & & Informing the captains of research vessels in advance about the planned presence of other vessels in the survey area \\
\hline
\end{tabular}

as low (2-4 weeks). Source of the risk is specified as internal and caused by human error. The proposed response strategy is mitigation by allowing joint decisions on suspending operations due to weather conditions by the party chief and the captain. Although the accuracy of weather forecasting has increased over time, it is not yet $100 \%$ accurate (Naresh et al. 2021). Taking into account the above regular weather analysis from several sources is necessary.

Measurement gear breakdown (R4) was determined as an unlikely event that can lead, among other results, to vessel layover despite favorable weather conditions and, in consequence, the project time extension frames up to 2 months. Source of the risk was determined as both external and internal caused by organization or technical issues. The manifestation of external weather risk could be the damage of infrastructure or survey equipment, which is often a result of "weather surprises," according to Wieczorek-Kosmala (2020) these kinds of events also have low frequency but potentially high consequences. Internal sources have organizational nature such as lack of proper procedures, noncompliance with procedures or instructions on the use of a given device. This type of weather risk exposure could be hedged with mitigation by regular maintenance of the equipment or providing training to the surveyors (Table 6).

Possible conflict with other users of the sea area (R5) was determined as unlikely with consequence to the schedules determined as low (2-4 weeks). The source was specified as external caused by organizational issues. The suggested risk response strategy is avoidance by setting the priority for each vessel and each activity.

Analyzing the above, it becomes clear that the risks identified as unlikely (R3, R4, R5) occurring individually have little consequences for the project implementation. The effects can be serious, when the accumulation of risks occurs or when we sum up their occurrence. Moreover, in the case of R3, while its frequency may be low, the damage caused in this case may be very severe.

\section{c. Limitations of our research}

This particular study has some limitations that are due to the sample size: there was only one company (Maritime Institute) operating in Poland that was the subject of this study. Because of the great experience of the Maritime Institute and a large number of completed offshore projects, we found that the derived results led to some interesting findings.

\section{d. Recommendations for future research}

Obtained results open the prospects for further research endeavors, as it raises several questions: How do companies operating in the offshore market deal with unpredictability of the weather conditions and therefore how do they manage weather risks while implementing investment projects and are the observations presented in this paper consistent with the situation in other companies operating in the market? Can there be identified any additional weather-related risks not mentioned in this paper that may depend on the scale of offshore investment projects or their specificities? What is the economic cost of weather-related delays on the offshore investment projects? Could a Baltic-wide recommendation, made by a decision-making body, mitigate economic consequences

TABLE 7. The R1 risk weight values determined for individual months (1-12) of the works conducted in survey locations A, B, and $\mathrm{C}$, in days. Source: internal data.

\begin{tabular}{ccrrrrrrrrrrr}
\hline \hline Station & 1 & 2 & 3 & 4 & 5 & 6 & 7 & 8 & 9 & 10 & 11 & 12 \\
\hline A & 14 & 10 & 7 & 5 & 3 & 3 & 4 & 4 & 7 & 11 & 11 & 17 \\
B & 15 & 11 & 9 & 7 & 4 & 5 & 6 & 6 & 8 & 12 & 12 & 18 \\
C & 11 & 8 & 6 & 5 & 4 & 3 & 5 & 4 & 6 & 9 & 8 & 14 \\
\hline
\end{tabular}


of weather risks? Last, how is this problem handled in other sea basins? To answer these questions, however, a wider examination needs to be conducted, with the application of methods that go beyond the information contained in reports prepared in one company and conducted only in the Polish EEZ. Further analysis of a larger number of documentation from projects carried out by other entities and interviews with a wider group of experts should provide enough material for more knowledge and experience on effective weather risk management.

\section{Conclusions}

In recent years, weather risk has become a very important category for many companies, despite the fact that the weather has always had an impact on the functioning of enterprises. The weather has a direct or indirect impact on the functioning of enterprises in the world, and the sectors most sensitive to changes in weather conditions are, in addition to the maritime industry, also energy, agriculture, tourism, and construction.

Weather is a key factor in the success of work carried out at sea. If it were possible to accurately forecast the weather for the entire period of any given project, the scope of the impact of the weather risk would be significantly reduced. Despite the development of forecast meteorology, today it is only possible to reliably forecast the weather in a period no longer than a few days, the longer the time horizon of the forecast, the lower the accuracy of the forecast. From the viewpoint of weather risk management in enterprises, this period is definitely too short (Czekaj 2016).

More and more often, project investors transfer the risks related to survey organization, including the weather conditions, onto the contractor. This paper reveals that finding the right weather-related risk analysis tool and creating a weather risk management plan will allow a reliable safe calculation of the project schedule and costs.

Effective weather risk management plan is fundamental. It should include weather-related risks identification and measurement, planning weather-related risk response methods, implementation of reserve plans, and allocation of reserves for any offshore project. Risk identification reduces the number of unforeseen events and the severity of their consequences. The paper proposes a risk analysis covering its qualification, assessment, and quantification. For this purpose, a risk matrix is created, which allows us to assess each identified risk probability and severity with the impact scale determined in terms of its consequences on the project schedule and time delays. Risks are classified as acceptable, risk that can hardly be accepted and as unacceptable risk. This allows awareness of the risks and enables the planning of appropriate measures to mitigate project delays.

The list of identified weather-related risks in the paper is far from being exhausted but they seem of universal and not uniquely Polish specific character. Moreover, the authors propose some concrete strategies for identified weatherrelated risks with examples. The main idea proposed to avoid the risk of surveys timed for the storm period is using statistical data from a wave motion model for time reserves expressed in the work days allotted for an individual task depending on the month and the location at which the works are conducted. Recognition of the meteorological conditions in the planned survey area is crucial for risk assessment and work schedule planning. Additional time reserves in the event of storms or sudden weather changes, however, should be taken into account throughout the year when planning activities at sea. Weather is also an indirect cause of complications and delays in conducting research. The ones we recognized are failure to start surveys despite favorable weather conditions, measurement gear breakdown or possible conflict with other users of the sea area. The present case can be treated as a starting point for more profound examinations of weather risk management plan in offshore projects.

In summary, this study is a step toward a quantitative method for generating satisfactory and optimal risk response plans to address project process weather-related risk factors. Our hope is that this research can provide an effective weather risk response tool to support offshore project stakeholders in improving their project's performance and ensuring its success.

Acknowledgments. The authors declare no conflict of interest.

Data availability statement. The data that support the findings of this study are available from the corresponding author upon justified request.

\section{REFERENCES}

Al-Zarrad, M. A., G. Moynihan, and S. Vereen, 2017: Weather derivatives as a risk management tool for construction projects. Sixth CSCE-CRC Int. Construction Specialty Conf. 2017, Vancouver, BC, Canada, Canadian Society for Civil Engineering, 1506-1514.

Barrieu, P., and O. Scailett, 2010: A primer on weather derivatives. Uncertainty and Environmental Decision Making, J. Filar and A. Haurie, Eds., International Series in Operations Research and Management Science, Vol. 138, Springer, 155-175, https:// doi.org/10.1007/978-1-4419-1129-2_5.

Campbell, S. D., and F. X. Diebold, 2005: Weather forecasting for weather derivatives. J. Amer. Stat. Assoc., 100, 6-16, https:// doi.org/10.1198/016214504000001051.

Chaouachi, A., C. F. Covrig, and M. Ardelean, 2017: Multi-criteria selection of offshore wind farms: Case study for the Baltic States. Energy Policy, 103, 179-192, https://doi.org/10.1016/ j.enpol.2017.01.018.

Cogen, J., 2020: What is weather risk? Retailenergy, http:// www.retailenergy.com/articles/weather.htm.

Czekaj, Z., 2016: Derywaty pogodowe jako instrument zarządzania ryzykiem pogodowym (Weather derivatives as an instrument of weather risk management). Ruch Prawniczy Ekon. Socjol., 78, 217-228, https://doi.org/10.14746/rpeis.2016.78.1.17.

Dalgic, Y., I. Lazakis, I. Dinwoodie, D. McMillan, and M. Revie, 2015: Advanced logistics planning for offshore wind farm operation and maintenance activities. Ocean Eng., 101, 211226, https://doi.org/10.1016/j.oceaneng.2015.04.040.

Dedecca, J. G., R. A. Hakvoort, and J. Roland Ortt, 2016: Market strategies for offshore wind in Europe: A development and diffusion perspective. Renewable Sustainable Energy Rev., 66, 286-296, https://doi.org/10.1016/j.rser.2016.08.007. 
Douard, F., C. Domecq, and W. Lair, 2012: A probabilistic approach to introduce risk measurement indicators to an offshore wind project evaluation-Improvement to an existing tool ECUME. Energy Procedia, 24, 255-262, https://doi.org/ 10.1016/j.egypro.2012.06.107.

Franzoni, S., and C. Pelizzari, 2016: Weather risk management in tourism industry. Symphonya Emerging Issues in Management, Milan, Italy, ISTEI 45-55, https://doi.org/ 10.4468/2016.1.05franzoni.pelizzari.

Gajewski, L., J. Gajewski, K. Kałas, A. Staśkiewicz, and K. Szefler, 2016: Optimum location of autonomous measurement stations on the southern Baltic. Bull. Marit. Inst., 31, 46-57.

Gatzert, N., and T. Kosub, 2016: Risks and risk management of renewable energy projects: The case of onshore and offshore wind parks. Renewable Sustainable Energy Rev., 60, 982-998, https://doi.org/10.1016/j.rser.2016.01.103.

Gintautas, T., J. D. Sørensen, and S. R. Vatne, 2016: Towards a risk-based decision support for offshore wind turbine installation and operation \& maintenance. Energy Procedia, 94, 207-217, https://doi.org/10.1016/j.egypro.2016.09.225.

Gobin, A., 2017: Weather related risks in Belgian arable agriculture. Agric. Syst., 159, 225-236, https://doi.org/10.1016/ j.agsy.2017.06.009.

Hac, B., and Coauthors, 2011a: Badania przedinwestycyjne w rejonach przewidywanej eksploatacji kruszyw: Raport z wykonania prac morskich Pola IIA, IIB, IIC (Pre-investment research in the areas of expected aggregate exploitation: Fields IIA, IIB, IIC sea works report). Maritime Institute Internal Publ. 6615, 33 pp.

— przewidywanej eksploatacji kruszyw: Raport $\mathrm{z}$ wykonania prac morskich Pola I (Pre-investment research in the areas of expected aggregate exploitation: Field I sea works report). Maritime Institute Internal Publ. 6614, 23 pp.

Herman-Iżycki, L., B. Jakubiak, K. Nowiński, and B. Niezgódka, 2002: UMPL-The numerical weather prediction system for operational applications. Research Works Based on the ICM's UMPL Numerical Weather Prediction System Results, Wydawnictwa ICM, 14-27.

Jamshidi, A., F. Jamshidi, D. Ait-Kadi, and A. Ramudhin, 2019: Applied risk analysis approaches for maintenance of offshore wind turbines; a literature review. IFAC-PapersOnLine, 52, 1075-1078, https://doi.org/10.1016/j.ifacol.2019.11.338.

Kałas, M., and K. Szefler, 2016: Applications of correlation functions to determine optimal locations of autonomous measuring buoys in the southern Baltic Sea. Bull. Marit. Inst., 31, 44-45.

—, A. Staśkiewicz, J. Gajewski, and K. Szefler, 2002: Wind characteristics in the Gulf of Gdańsk area from HIRLAM and UMPL models in comparison with the measurements from MIG-1 buoy. J. Environ. Chem. Phys., 24, 206-212.

Komen, G. J., L. Cavalieri, M. Donelan, K. Hasselmann, S. Hasselmann, and P. A. E. N. Janssen, 1994: Dynamics and Modelling of Ocean Waves. Cambridge University Press, $554 \mathrm{pp}$.

Lapeña, P., K. M. Blanca, S. J. M. H. Hulscher, and A. Stein, 2010: Environmental impact assessment of offshore wind farms: A simulation-based approach. J. Appl. Ecol., 47, 1110-1118, https://doi.org/10.1111/j.1365-2664.2010.01850.x.

Leimeister, M., and A. Kolios, 2018: A review of reliability-based methods for risk analysis and their application in the offshore wind industry. Renewable Sustainable Energy Rev., 91, 10651076, https://doi.org/10.1016/j.rser.2018.04.004.
Li, X., and Coauthors, 2016: A decision support system for strategic maintenance planning in offshore wind farms. Renewable Energy, 99, 784-799, https://doi.org/10.1016/ j.renene.2016.07.037.

Mentel, G., and J. Nakonieczny, 2019: Weather risk and energy consumption in Poland. Energy Transformation towards Sustainability, Elsevier, 113-132.

Meyer, M. D., E. Rowan, M. J. Savonis, and A. Choate, 2012: Integrating extreme weather risk into transportation asset management. American Association of State Highway and Transportation Officials Doc., 19 pp.

Ministry of Climate and Environment, 2020: Energy Policy of Poland until 2040. Government of Poland Rep., 102 pp., https://www.gov.pl/attachment/62a054de-0a3d-444d-a96990a89502df94.

Mraoua, M., and D. Bari, 2007: Temperature stochastic modeling and weather derivatives pricing: Empirical study with Moroccan data. Afrika Stat., 2, 22-43, https://doi.org/10.4314/ afst.v2i1.46865.

Myhr, A., C. Bjerkseter, A. Ågotnes, and T. A. Nygaard, 2014: Levelised cost of energy for offshore floating wind turbines in a lifecycle perspective. Renewable Energy, 66, 714-728, https://doi.org/10.1016/j.renene.2014.01.017.

Mytilinou, V., and A. J. Kolios, 2019: Techno-economic optimisation of offshore wind farms based on life cycle cost analysis on the UK. Renewable Energy, 132, 439-454, https://doi.org/ 10.1016/j.renene.2018.07.146.

Naresh, R. K., S. Kumar, and E. Narwal, 2021: Weather forecasting. Artificial Intelligence in Indian Agriculture, R. K. Naresh et al., Eds., Jaya Publishing, 1-16.

Nielsen, J. J., and J. D. Sørensen, 2011: On risk-based operation and maintenance of offshore wind turbine components. Reliab. Eng. Syst. Saf., 96, 218-229, https://doi.org/10.1016/j.ress.2010.07.007.

OSPAR Commission, 2008: Assessment of the environmental impact of offshore wind-farms. Biodiversity Series Doc., 35 pp., https://www.ospar.org/documents? $v=7114$.

Poulsen, T., and R. Lema, 2017: Is the supply chain ready for the green transformation? The case of offshore wind logistics. Renewable Sustainable Energy Rev., 73, 758-771, https:// doi.org/10.1016/j.rser.2017.01.181.

Pritchard, C., 2001: Risk Management, Concepts and Guidance. 2nd ed. ESI International, $340 \mathrm{pp}$.

Polska Grupa Energetyczna, 2015: The first Polish nuclear power plant. Project Information Sheet PGE EJ $1 \mathrm{sp.}$ z o.o, 220 pp., https://2015-2019.kormany.hu/download/7/ b1/a0000/Environmental\%20Scoping\%20Report\%20PGE_ SCN_DES_0001_EN.pdf.

Project Management Institute, 2000: A Guide to the Project Management Body of Knowledge (PMBOK Guide). Project Management Institute, $592 \mathrm{pp}$.

Shafiee, M., 2015: A fuzzy analytic network process model to mitigate the risks associated with offshore wind farms. Expert Syst. Appl., 42, 2143-2152, https://doi.org/10.1016/j.eswa.2014.10.019.

_ , F. Brennan, and I. A. Espinosa, 2015: Towards whole lifecycle costing of large-scale offshore wind farms. European Wind Energy Association Annual Conf. and Exhibition 2015, Paris, France, European Wind Energy Association, 140-144.

Stryjecki, M., and Coauthors, 2019: Baltic pipe offshore pipeline-Polish part. Environmental Impact Assessment Rep., 167 pp.

Szefler, K., and Coauthors, 2017: Report on the environmental impact of the Baltica Offshore Wind Farm (in Polish). Consortium of Maritime Institute in Gdańsk and MEWO 
Rep., 500 pp., http://www.portalgis.gdansk.rdos.gov.pl/ morskafarmawiatrowa-Baltica/Raport_OOS_PL_vA.pdf.

Tseng, Y. C., Y. M. Lee, and S. J. Liao, 2017: An integrated assessment framework of offshore wind power projects applying equator principles and social life cycle assessment. Sustainability, 9, 1822, https://doi.org/10.3390/su9101822.

Wieczorek-Kosmala, M., 2020: Weather risk management in energy sector: The Polish case. Energies, 13, 945, https://doi.org/ 10.3390/en13040945.

Williams, H., I. Masters, D. Pletsas, C. Fuentes Grunewald, R. Callaway, G. Dalton, and M. Blanch, 2017: A risk assessment methodology for combining marine renewables with other blue economy activities via multi-use of spaces and platforms. Proc. 12th European Wave and Tidal Energy Conf., Cork, Ireland, EWTEC, 817-1-817-9.

WindEurope, 2020: Offshore wind in Europe-Key trends and statistics 2019. WindEurope Rep., 40 pp., https://windeurope.org/ wp-content/uploads/files/about-wind/statistics/WindEuropeAnnual-Offshore-Statistics-2019.pdf.

Wyrozębski, P., 2012: Zarzadzanie ryzykiem w projekcie (Project risk management). Nowoczesne Zarzadzanie Projektami (Modern Project Management), M. Trocki, Ed., Polish Economic Society, 296-306.

Yu, J., 2018: 5 basic methods for risk management. Investopedia, https://www.investopedia.com/articles/investing-strategy/082816/ methods-handling-risk-quick-guide.asp. 